\title{
A COMPARATIVE STUDY ON EFFICACY OF COLLAGEN PEPTIDE ACECLOFENAC AND PARACETAMOL VERSUS ACECLOFENAC AND PARACETAMOL ALONE FOR THE TREATMENT OF KNEE OSTEOARTHRITIS.
}

\author{
Mareena Raju*, Blessy K Johnson, Ambarish Sharma, Bharathi DR \\ SJM College of Pharmacy, Chitradurga-577502
}

Article Info: Received 24 March 2019; Accepted 26 April. 2019

Cite this article as: Raju, M., Johnson, B. K., Sharma, A., \& R, B. (2019). A COMPARATIVE STUDY ON EFFICACY OF COLLAGEN PEPTIDE ACECLOFENAC AND PARACETAMOL VERSUS ACECLOFENAC AND PARACETAMOL ALONE FOR THE TREATMENT OF KNEE OSTEOARTHRITIS. Journal of Biomedical and Pharmaceutical Research, 8(2).

DOI: https://doi.org/10.32553/jbpr.v8i2.593

Address for Correspondence: Mareena Raju,Pharm D Intern,SJM College of Pharmacy, Chitradurga-577502

Conflict of interest statement: No conflict of interest

\section{ABSTRACT:}

Background: The existing treatment for Osteoarthrits (OA) is symptomatic by NSAIDS are effective for reducing pain associated with OA, they do not reverse the disease. This makes way for the emergence of nutraceuticals like collagen peptide which are chondroprotective in nature.

Objectives: To assess the prevalence of knee OA, efficacy of combination of collagen peptide, aceclofenac and paracetamol against aceclofenac and paracetamol alone in the treatment of osteoarthritis, the medication adherence and drug related problems in OA.

Methods: A prospective observational study was carried out in the outpatients of Department of Orthopaedics, BMCH \& RC and Ambarish's Clinic, Chitradurga. A total of 154 patients suffering from OA were identified. 60 subjects of Grade I knee OA were selected for the study from 112 cases of knee OA. The subjects were divided in two groups; Group A comprised of 30 subjects who were treated with collagen peptide, aceclofenac and paracetamol (Acetaminophen) for a period of two months, with a follow up of one month and the therapy was assessed by Visual Analogue Scale(VAS). Whereas Group B of 30 subjects who were treated with aceclofenac and paracetamol for two months with a follow up of one month and assessed by VAS.

Results: The prevalence of knee osteoarthritis was found to be $72.72 \%$.Among them Grade I was 77.67\%. From this 60 patients were selected for further study of which $90 \%$ were females and $10 \%$ males. At the end Group A showed better results than Group B. Acetaminophen and Aceclofenac related gastrointestinal disturbances were found in both the groups. Majority of the patients also had good medication adherences.

Conclusion: The study identifies and supports the use of collagen peptide to provide symptomatic relief and can be used as adjunct therapy for OA management.

Keywords: Knee osteoarthritis, nutraceuticals, collagen peptide, Visual Analogue Scale.

\section{Introduction}

The two most common types of arthritis are osteoarthritis (OA) and rheumatoid arthritis (RA). OA of the knee and hip is a growing health concern and is the most common forms of arthritis.

Due to the lack of self-healing capacity of articular cartilage, $\mathrm{OA}$ is among the most 
challenging joint diseases and there is currently no cure for it and available treatment is mostly symptomatic, which is revolved around pain relief with agents such as paracetamol, topical and systemic nonsteroidal anti-inflammatory drugs, intra-articular corticosteroids, and visco- supplementation. The perfect drug would be not only able to relieve inflammation and pain but also to slow down, stop or even better prevent disease progression. This would result in the maintenance of joint function, sparing joint structures involved in $\mathrm{OA}$, meaning cartilage, synovial membrane and subchondral bone.

Several studies show that enzymatically hydrolysed collagen (known as gelatin hydrolysate or collagen hydrolysate or collagen peptide) is absorbed and distributed to joint tissues and has analgesic and antiinflammatory properties.

\section{Materials and Methods}

Study Site: The study was conducted in Basaveshwara Medical College Hospital and Research Centre and Ambarish's Clinic, Chitradurga.

Study design: It is a prospective observational study.

Study period: The study was conducted for a period of six months from 2017 to 2018.

Study subjects: The study included the subjects who meet the following criteria

\section{Inclusion Criteria:}

* Subjects of either sex with the diagnosis of knee osteoarthritis.

* Subjects of all age groups who fall under grade 1 knee osteoarthritis.

* Subjects who are willing to give inform consent form (ICF).

\section{Exclusion Criteria:}

* Subjects who have DM.

\section{Sources of data:}

Subjects meeting the study criteria were included in the study after explaining about the study in their local language and obtaining their informed consent. Subject's demographic details, social habits, socio economic condition, past medication history, known allergies to food and drugs were collected from subject's case sheets (includes inpatient case record and OPD record) interview with subjects and/or their care takers and health care professionals.

\section{Study procedure:}

Subjects who satisfy the above criteria were enrolled for the study.

Subjects' demographic details including name, age, gender, diagnosis as well as current medication therapy was brought into a Case Record Book for further follow up.

Subjects were assigned to two groups that is, Group A comprises of 30 subjects who were treated with collagen peptide(10.8g), aceclofenac(100mg) and paracetamol (Acetaminophen $325 \mathrm{mg}$ ) for a period of two months, follow up done every month and the therapy was assessed by Visual Analogue Scale(VAS). Whereas Group B also comprised of 30 subjects who were treated with aceclofenac(100mg) and paracetamol(Acetaminophen $325 \mathrm{mg}$ ) for two months with a follow up of one month and the therapy was assessed by VAS.

\section{Statistical Analysis:}

The demographic details of the patients were analysed using descriptive statistics. Categorical data were analyzed by frequency \& Percentage method. Quantitative data was analyzed by central tendency distribution. The VAS score was analysed using graphical method.

\section{Results}

A total of 154 subjects who visited the Orthopaedics Outpatient Department during the study period were suffering from osteoarthritis, in which $112(72.72 \%)$ subjects 
were presented with knee osteoarthritis (KOA), 29(18.83\%) were with hip osteoarthritis (HOA) and $13(8.45 \%)$ with shoulder osteoarthritis (SOA).

Table 1: Details of Prevalence of Knee Osteoarthritis

\begin{tabular}{|l|l|l|l|l|}
\hline SI. No & Prevalence of Osteoarthritis & Code & Total In No. & $\%$ \\
\hline 1 & Knee Osteoarthritis & KOA & 112 & 72.72 \\
\hline 2 & Hip Osteoarthritis & HOA & 29 & 18.83 \\
\hline 3 & Shoulder Osteoarthritis & SOA & 13 & 08.45 \\
\hline & Total & & 154 & 100 \\
\hline
\end{tabular}

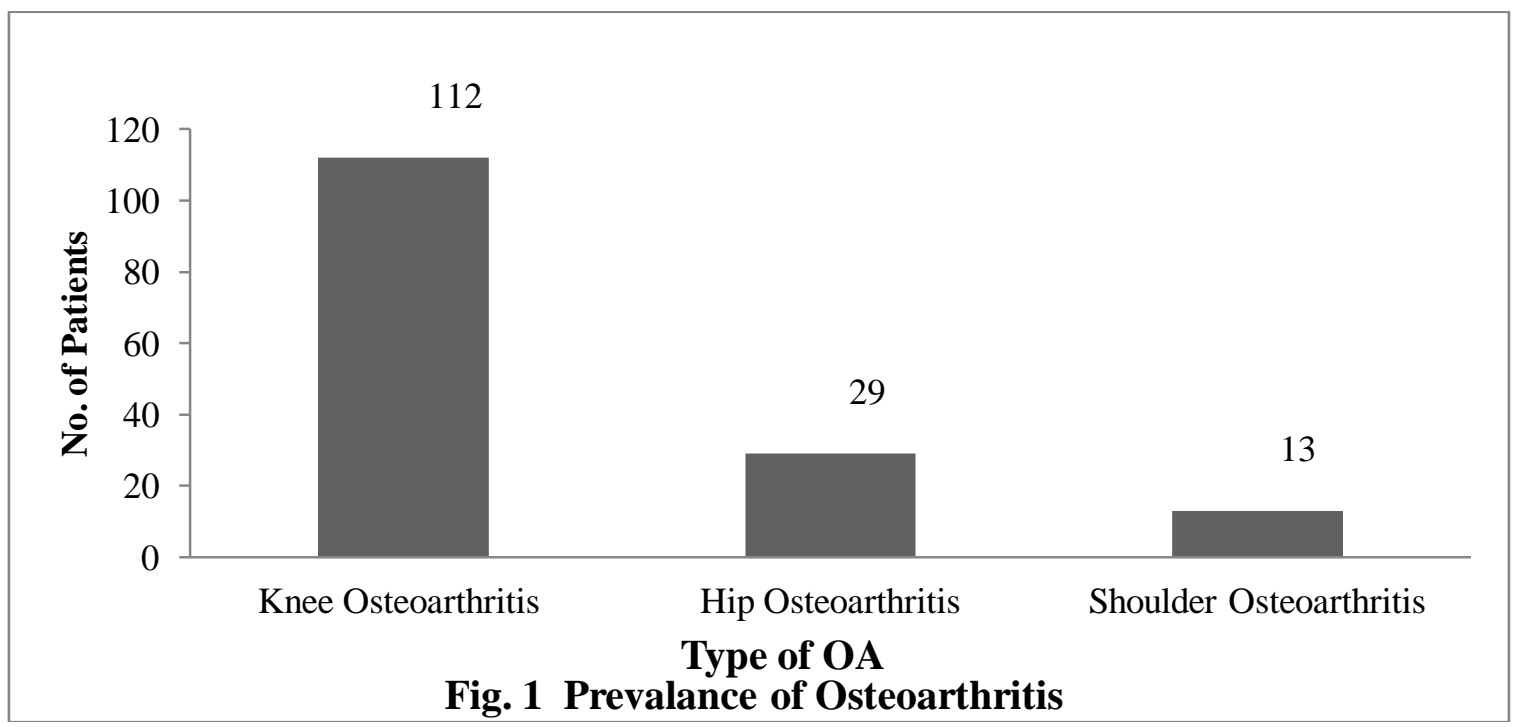

These 112 subjects were undergone radiographic imaging for categorising them into different types of KOA based on Kellgren-Lawrence radiologic classification. According to Kellgren-Lawerence classification scale for osteoarthritis severity, Grade 1 is to have a doubtful narrowing of joint space, possible osteophytic lipping, Grade 2 possible narrowing of joint space, definite osteophytes, where Grade 3 have definite narrowing of joint space, moderate multiple osteophytes, some subchondral sclerosis, possible deformity of bone ends and Grade 4 have marked narrowing of joint space, large osteophytes, severe subchondral sclerosis, definite deformity of bone ends. The sixty osteoarthritis patients that entered the study were equally randomized to the two treatment groups, Group $A$ and Group B. Over the course of the study, two patients dropped out of group A (had already taken collagen peptides before the study).

The VAS scores of both the groups are summarised in tables $2 \& 3$ and fig. $2 \& 3$.

Table 2: VAS scores of Group A subjects.

\begin{tabular}{|l|l|l|l|}
\hline Visit & base line & visit 1 & visit 2 \\
\hline mild 2 & $\mathbf{0}$ & $\mathbf{0}$ & $\mathbf{4}$ \\
\hline mod-5 & $\mathbf{0}$ & $\mathbf{0}$ & $\mathbf{1 2}$ \\
\hline mod-6 & $\mathbf{0}$ & $\mathbf{1 1}$ & $\mathbf{1 2}$ \\
\hline sev-7 & $\mathbf{3}$ & $\mathbf{1 4}$ & $\mathbf{2}$ \\
\hline sev-8 & $\mathbf{1 2}$ & $\mathbf{5}$ & $\mathbf{0}$ \\
\hline sev-9 & $\mathbf{1 5}$ & $\mathbf{0}$ & $\mathbf{0}$ \\
\hline
\end{tabular}


Mareena Raju et al, Journal of Biomedical and Pharmaceutical Research

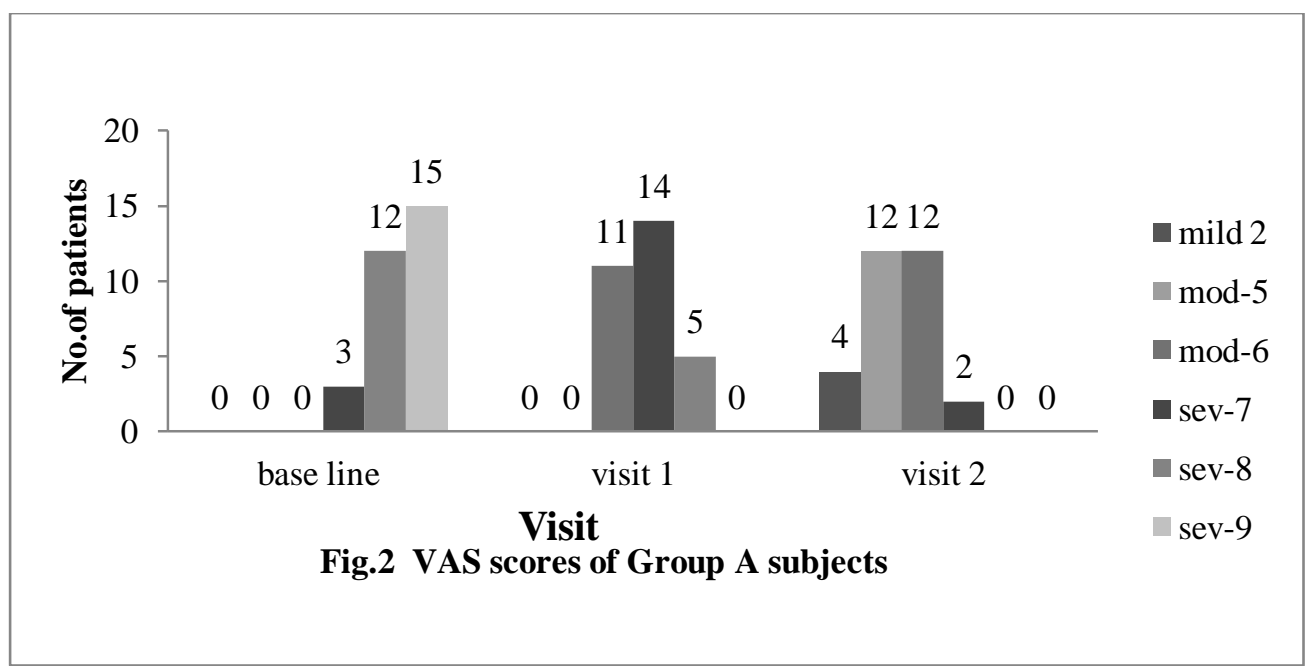

Table 3: VAS scores of Group B subjects.

\begin{tabular}{|l|l|l|l|}
\hline Visit & base line & visit 1 & visit 2 \\
\hline mod-5 & 0 & 6 & 4 \\
\hline mod-6 & 6 & 11 & 6 \\
\hline sev-7 & 14 & 7 & 11 \\
\hline sev-8 & 4 & 5 & 7 \\
\hline sev-9 & 5 & 1 & 2 \\
\hline
\end{tabular}

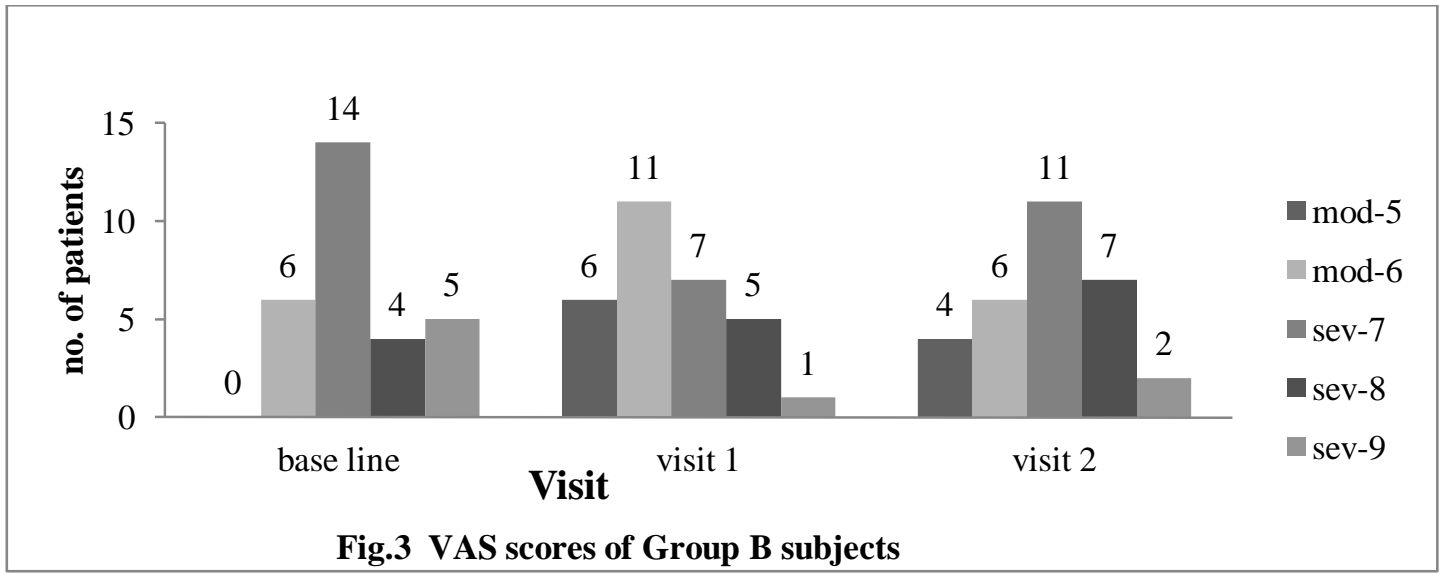

Among 60 subjects treated with Aceclofenac and Paracetamol, 6 from both groups experienced an adverse event of gastric irritation and one from group B experienced lightheadedness. The adverse events were reported to be mild in nature and were relieved with concomitant medication. Relative data is given in table 4 and graphically in figure 4.

Table 4: Adverse events reported

\begin{tabular}{|l|l|l|}
\hline Adverse event & group A & group B \\
\hline gastric disturbance & 6 & 6 \\
\hline light headedness & 0 & 1 \\
\hline no problems & 24 & 23 \\
\hline
\end{tabular}




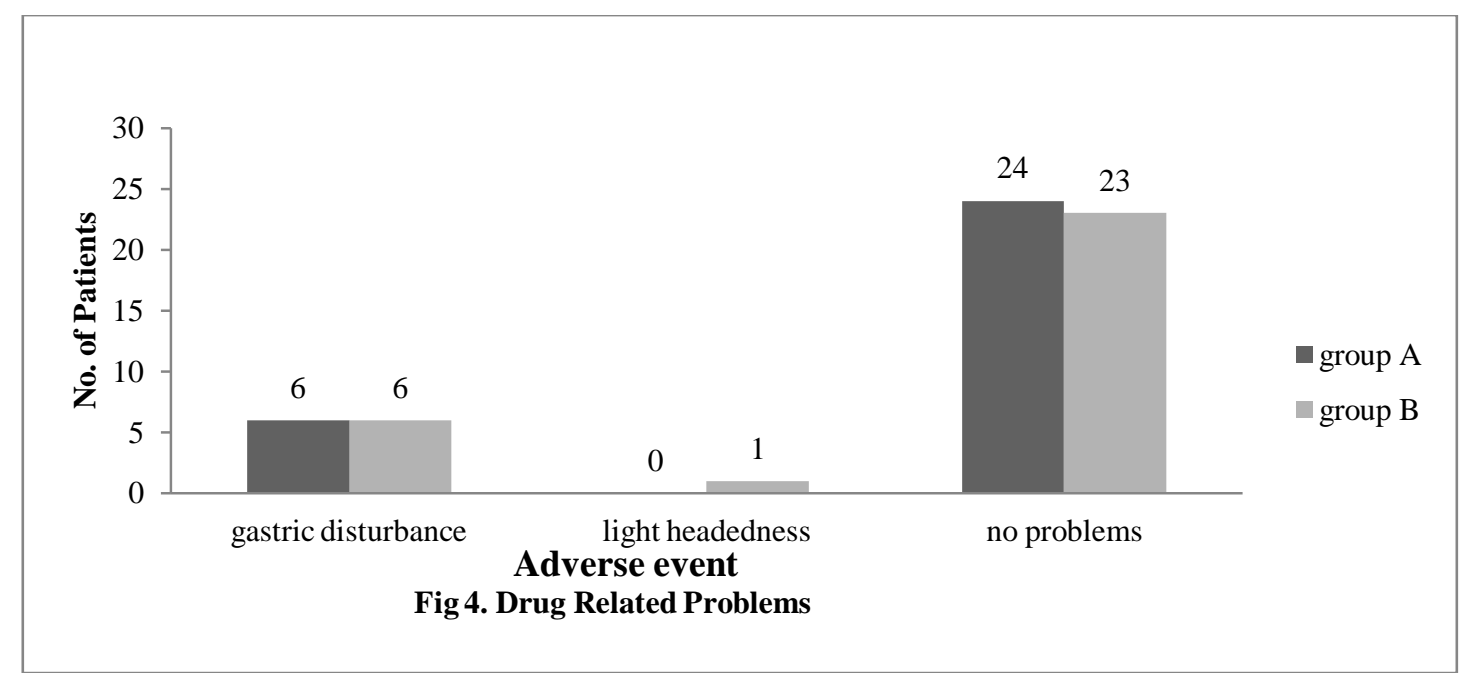

Medication adherences of the subjects were monitored through telephonic interviews. Majority of the subjects showed good medication adherences, whereas a few showed poor adherences.

\section{Discussion}

A total of 154 subjects have been found to be suffering from osteoarthritis, out of which the prevalence of knee osteoarthritis were 112 (72.72\%). Our findings represented in figure 1 , were similar to the study conducted by Radha $S$ (2015) et al., that KOA is a common condition which represents a major contribution to the burden of physical disability. The 60 KOA subjects who entered the study were categorised into Group A of 30 subjects who further underwent therapy for 2 months which comprises of Aceclofenac (100mg), Paracetamol (325mg) and Collagen Peptide(10.8g) and the other 30 into Group B which had a treatment regimen of Aceclofenac (100mg), Paracetamol (325mg) for two months. A review conducted by Moskowitz RW (2000) states that daily dose of $10 \mathrm{gm}$ is optimum in reducing the pain related to osteoarthritis which further coincides with the dose we used. The pain levels were assessed with VAS. The VAS scores from baseline visit to visit two shows significant decrease in severity of the pain. The group A had 3 patients complaining of severe 7 pain score, 12 with severity 8 and 15 with severity 9 at the time of the baseline visit. The severity level decreased significantly at the time of second visit which is well presented graphically in figure 2. During the second visit only 2 subjects had pain of severity 7 whereas others experienced pain in a much less intensity as follows; 12 subjects with moderate 6,12 subjects with moderate 5 and 4 with mild 2. Group B also showed decrease in their pain levels but not in similar sequence. At the time of baseline visit the pain levels of the subjects were 5 with severe 9,4 with severe 8, 14 with severe 7, 6 with moderate 6 . The first visit showed a decrease in severe 9 pain level and increase in the lower pain levels. In the case of the second visit there was an increase in severe 9 count along with severe 8 and severe 7.The results are graphically presented in fig.3. The descriptive display of the results clearly demonstrates the efficacy of collagen peptide, aceclofenac and paracetamol over aceclofenac and paracetamol alone for the treatment of KOA. The clinical data collected in this study is well supported by the results of other congruent studies like of Bernado and Azarcon Jr.(2012) which confirms the effect of collagen peptide on joint symptoms as well as improving the functional status in patients diagnosed with OA. The results point towards the direct impact collagen peptide has on the joint cartilage. Among 60 subjects, 6 from each group were having aceclofenac and 
paracetamol induced gastric disturbances, one had light headedness. Since there are many established articles and evidence based studies for long term NSAID induced adverse effects like gastrointestinal disturbances, here we have considered the study by Crofford J (2013), which is similar to our study. Other adverse effects related to the use of collagen peptide were not reported during the study. In the study conducted by Jiang et al., in the Chinese population showed no adverse effects but the study conducted by Kumar $S$ et al., in the Indian population did. In the study among 20 subjects treated with PCP, only one experienced an adverse event of allergic peripheral oedema and among 20 subjects treated with $\mathrm{BCP}$, three subjects experienced adverse events such as vomiting, diarrhoea and common cold. Therefore we need further detailed studies to analyse the adverse events caused by Collagen peptide in our population. Other adverse effects related to the use of collagen peptide were not reported during the study. In the study conducted by Jiang et al., in the Chinese population showed no adverse effects but the study conducted by Kumar $\mathrm{S}$ et al., in the Indian population did. In the study among 20 subjects treated with $\mathrm{PCP}$, only one experienced an adverse event of allergic peripheral oedema and among 20 subjects treated with $\mathrm{BCP}$, three subjects experienced adverse events such as vomiting, diarrhoea and common cold. Therefore we need further detailed studies to analyse the adverse events caused by Collagen peptide in our population.

\section{Conclusion}

We conducted a 6 months observational study for comparing the efficacy of collagen peptide, aceclofenac and paracetamol versus aceclofenac and paracetamol alone for the treatment of KOA. With the results obtained following conclusions are made:

1. KOA is the most common form osteoarthritis and the risk of getting KOA progresses with age. Females are more affected than males.
Obesity is the most prominent contributing factor.

2. The current study showed significant pain reduction in both the treatment groups, but Group A had a higher decrease in pain also, there was improvement in the joint space .There were 4 cases of improved joint space on account of collagen peptide administration. The study authenticate that collagen peptide is effective in improving the physical problems associated with $\mathrm{OA}$ and improving the quality of life. It is hypothesised that the supplementation of collagen peptide regulates chondrocyte differentiation and stimulates synthesis of proteoglycans, resulting in the initiation of repair processes in cartilage tissue.

3. NSAID associated adverse effects were found in both study groups. Drug problems related to use of collagen peptide needs further study.

4. Greater part of the patients had a good medication adherence.

Overall, the study identifies and supports the use of collagen peptide to provide symptomatic relief to patients with $O A$ and to be used as adjunct therapy for OA management.

According to the analyzed results and from review of literature Collagen peptides are nutraceuticals used in dietary supplements and as a food ingredient offering health benefits at different levels. Their positive effect on skin physiology, increasing skin hydration and elasticity, stimulating synthesis of skin matrix components and decreasing skin collagen fragmentation is well documented.

\section{Acknowledgement}

It is a pleasure and privilege to express my deep sense of thanks and indebtedness to the management of SJM College of Pharmacy Karnataka, Dr. Bharathi D.R, Principal SJM College of Pharmacy and Dr. Ambarish Sharma 
for giving the consent and facilities to carry out this work.

\section{References:}

1. Crowley DC, Lau FC, Sharma P, Evans M, GuthrieN, Bagchi $M$, et al. Safety and efficacy of undenatured type II collagen in the treatment of osteoarthritis of the knee: a clinical trial; International Journal of Medical Sciences 2009; 6(6):312-21.

2. Jiang J, Yu S, Huang $Q$, Zhang $X$, Zhang $C$, Zhou J, Prawitt J. Collagen peptides improve knee osteoarthritis in elderly women ; A 6-month randomized, doubleblind, placebo-controlled study; Agro FOOD Industry Hi Tech ,2014;25(2): 19-23.

3. Kumar S, Sugihara F, Suzuki K, Inoue and Venkateswarathirukumara S. A doubleblind, placebo-controlled, randomised, clinical study on the effectiveness of collagen peptide on osteoarthritis; J Sci Food Agric (2014) (wileyonlinelibrary.com) DOI 10.1002/jsfa.6752.

4. Henrotin $Y$,Lambert $C$,Couchourel D, Ripoll E , Chiotelli E. Nutraceuticals: do they represent a new era in the management of osteoarthritis? A narrative review from the lessons taken with five products; Osteoarthritis and Cartilage 19 (2011) 1e21.

5. Zhang $W$, Ouyang $H$, Dass $C R$ and $X u J$. Current research on pharmacologic and regenerative therapies for osteoarthritis; Bone Research (2016) 4, 15040; doi:10.1038/boneres.2015.40.

6. Radha MS and Gangadhar MR. Research Article Prevalence Of Knee Osteoarthritis Patients In Mysore City, Karnataka; International Journal of Recent Scientific Research April 2015;6(4):3316-20.

7. Moskowitz RW. Role of Collagen Hydrolysate in Bone and Joint Disease; Seminars in Arthritis and Rheumatism, Vol 30, No 2 (October), 2000: pp 87-99.

8. Bernardo $\mathrm{ML}$ and Azarcon, Jr.A. A Randomized Controlled Trial on the Effects of Oral Collagen Treatment on the Media) Knee Joint Space aod Functional Outcome among Veterans Memorial Medical Center Patients Diagnosed with Osteoarthritis of the Knee; Pharm proceedings 4(1)2012.

9. Crofford $\amalg$. Use of NSAIDs in treating patients with arthritis; Croff ord Arthritis Research \& Therapy 2013, 15(Suppl 3):S2 http://arthritis-research.com/content /15/ S3/S2.

10. Chitragar DD,Shaikh S I. Variables Associated With Knee Osteoarthritis In A Tertiary Care Hospital Of Tamilnadu, India; National Journal Of Medical Research Apr - Jun 2016;6(2):119-23.

11. Basu $S$ and Abby C. King. Disability and Chronic Disease Among Older Adults in India: Detecting Vulnerable Populations Through the WHO SAGE Study; Am J Epidemiol. 2013;178(11):1620-1628.

12. Henrotin $Y$, Lambert $C$,Couchourel D, Ripoll E , Chiotelli E. Nutraceuticals: do they represent a new era in the management of osteoarthritis? A narrative review from the lessons taken with five products; Osteoarthritis and Cartilage 19 (2011) 1e21.

13. Zhang W, Ouyang $H$, Dass $C R$ and $X u J$. Current research on pharmacologic and regenerative therapies for osteoarthritis; Bone Research (2016) 4, 15040; doi:10.1038/boneres.2015.40.

14. Porfírio E. Collagen supplementation as a complementary therapy for the prevention and treatment of osteoporosis and osteoarthritis: a systematic review; Rev. Bras. Geriatr. Gerontol, Rio de Janeiro, 2016; 19(1):153-64.

15. Milder TY, Williams KM , Ritchie JE, Lipworth LW, Day RO. Use of NSAIDs for osteoarthritis amongst older-aged primary care patients: engagement with information and perceptions of risk; Oxford University Press on behalf of the British Geriatrics Society. doi: 10.1093/ ageing/afq174. 
Mareena Raju et al, Journal of Biomedical and Pharmaceutical Research

16. Henrotin $Y$, Berenbaum $F$, Chevalier $X$, Marty $M$, Richette $P$ and Rannou $F$. Reduction of the Serum Levels of a Specific Biomarker of Cartilage Degradation (Coll21) by Hyaluronic Acid (KARTILAGE ${ }^{\circledR}$ CROSS) Compared to Placebo in Painful Knee Osteoarthritis Patients: the EPIKART Study, a Pilot Prospective Comparative Randomized Double Blind Trial; BMC Musculoskeletal Disorders (2017) 18:222 DOI 10.1186/s12891-017-1585-2.

17. Huntler DJ. Viscosupplementation for Osteoarthritis of the Knee, N Engl J Med, 2015;372:1040-47. 